\title{
Diet Behavior Modification of Pregnant Woman with Iron Deficiency Anemia Using Construct of the Trans-Theoretical Model: A Theory-Based Study
}

\author{
Heba Abdel-Fatah Ibrahim ${ }^{1}$, Hanan Abd Elwahab El Sayed ${ }^{2}$ \\ Ebtisam Mohamed Abd El-aal ${ }^{2}$ \\ ${ }^{1}$ Obstetrics and Woman Health Nursing, Benha University, Benha, Egypt \\ ${ }^{2}$ Community Health Nursing, Benha University, Benha, Egypt
}

\begin{abstract}
:
Background: Iron deficiency anaemia is a major cause of morbidity and mortality of pregnant women and increases the risks of foetal, neonatal and infant mortality. Nutritional education, with special emphasis on strategies based on locally available food stuffs to improve the dietary intake of proteins and iron is important during pregnancy. This study aimed to evaluate diet behaviour of pregnant woman with iron deficiency anaemia before and after the implementation of educational intervention based trans-theoretical model of change.

Methods: A quasi-experimental design was utilized. Setting: The study was conducted at obstetrics and gynecology outpatient clinic affiliated to Benha teaching hospital. A purposive sample of 73 pregnant women were included in the current study. Two tools were used for data collection; first tool interviewing questionnaire to collect data about the subjects' socio-demographic data, medical and obstetric history and knowledge regarding iron deficiency anemia. Second tool; the trans-theoretical model of behavior change questionnaire, it composed of the four main constructs that are stage of change, self-efficacy, decisional balance (pros and cons), experiential and behavioral process of change.
\end{abstract}

Results: There were highly statistically significant differences $(P<.001)$ regarding to pregnant women' knowledge, and trans-theoretical model constructs include self-efficacy, decisional balance (pros, cons), experiential and behavioral processes of change after the intervention based trans-theoretical model as compared to before. Also, $24.7 \%$ of the pregnant women were free from anemia after intervention based transtheoretical model.

Conclusion and recommendation: The application of trans-theoretical model of behavior change was effective in improving pregnant women's knowledge and diet behavior regarding iron deficiency anemia. The nurse should implement educational intervention based on trans-theoretical for anaemic pregnant women regarding diet behaviour modification.

Keyword: Diet behaviour, Iron deficiency anaemia, Pregnant woman, Trans-theoretical model.

\section{Introduction}

Anaemia is considered a global public health problem; playing an important contributor to morbidity and mortality among pregnant women, especially in developing countries. ${ }^{[1]}$ Women of childbearing age are most at risk, with global anemia prevalence estimates of 30\% in non-pregnant women and $42 \%$ in pregnant women aged 15-49 years and with Africa and Asia accounting for more than $85 \%$ of the absolute anaemia burden in high risk groups where its causes are multi-factorial. ${ }^{[2]}$

Anemia is a deficiency of functioning red blood cells (RBCs) that leads to a decrease of oxygencarrying ability, causing unusual complications during life time ${ }^{[3]}$ According to WHO, Iron deficiency is the most common nutritional deficiency in the world, affecting about $25 \%$ of the world population, especially women in the childbearing age. It is more common in pregnancy because a pregnant woman needs to have enough RBCs to carry oxygen around her body as well as to her baby. It is considered severe when hemoglobin $(\mathrm{Hb})$ concentration is less than $7.0 \mathrm{~g} / \mathrm{dl}$, moderate when $\mathrm{Hb}$ level is $7.0-9.9 \mathrm{~g} / \mathrm{dl}$, and mild when $\mathrm{Hb}$ level is 10.0 $-10.9 \mathrm{~g} / \mathrm{dl} .^{[4]}$

Iron deficiency anemia (IDA) is a condition characterized by significant lack of iron storage in the body as a result to a variety of extrinsic and intrinsic factors. This type of anemia is hypochromic and microcytic in nature. pregnant and lactating women, infants, women of childbearing age, elderly adults, patients with major blood loss, individuals with nutritionally-poor diets, and low socioeconomic classes, are examples of populations most liable to IDA. ${ }^{[5,6]}$ Women who are older than 30 years, had more than three children, with body mass index less than 20 , shorter birth spacing less than 2 years, lack of antenatal care visits, low intake of foods of animal source, vegetables and fruits and having intestinal parasites were positively associated with anaemia. ${ }^{[7]}$ 
During pregnancy, IDA is associated with typical features caused by lowered oxygen delivery to the tissues, and includes fatigue, pallor, emotional instability, depression, fainting, breathlessness, headaches, palpitation, hair loss, and tinnitus. In addition, chronic IDA lowers productivity, work tolerance, and the quality of life. This leads to further socio-economic problems. Moreover, dysfunction in the immune system results in increased risks for infections. ${ }^{[8,9]}$

Anaemia resulting from iron deficiency has a significant impact on the health of the fetus and the mother which adversely affects cognitive and motor development, causes fatigue and low productivity. ${ }^{[10]}$ Also, may be associated with low birth weight, premature labor, intrauterine growth retardation, and increased risk of maternal and prenatal mortality. ${ }^{[11]}$ In developing regions, maternal and neonatal mortality were responsible for 3.0 million deaths in 2013 and are important contributors to overall global mortality. ${ }^{[12]}$

Iron supplementation is the primary treatment for IDA, Iron-rich foods and iron-fortified foods are also recommended for women with IDA and especially those with major risk factors for IDA or already diagnosed with IDA. ${ }^{[13]}$ Iron is an essential component of $\mathrm{Hb}$, an erythrocyte protein that transfers oxygen from the lungs to the tissues. Dietary iron has two main forms: heme and nonheme. Plants and iron-fortified foods contain nonheme iron only, whereas meat, seafood, and poultry contain both heme and nonheme iron. ${ }^{[14]}$ The dietary guidelines advise pregnant to take an iron supplement when recommended by an obstetrician. ${ }^{[15]}$ Dietary modification is the main treatment of iron deficiency with an emphasis on iron-rich food sources, especially sources of haem iron such as red meat, chicken and fish, consumed with foods high in vitamin $\mathrm{C}$ to help the body absorb the iron. High consumption of absorption inhibitors should be avoided such as tea, coffee or fiber. ${ }^{[16]}$

Early detection and management strategies should be implemented to prevent complications of IDA. Research studies should be directed to assess the needs of pregnant women. The main focus of research studies should be behavior and life style modification of individual. The approach of primary prevention should be adopted, which includes preventing anemia and spread of risk factors and lifestyle modification through health education programs conducted by the nursing staff both in hospital and community. ${ }^{[17]}$

The Trans theoretical Model (TTM) of Behavior Change provides new and helpful insights for health education. Also, it explains the process of how people attempt to modify health-risk behaviors. It is successfully applied to a variety of health behavior areas, including smoking cessation, weight control, dietary change, exercise acquisition, and stress management. Within this model, there are sets of common principles that explain why people succeed and fail in changing their behavior. Research has provided strong support for the reliability and validity of the model's core constructs, including stages of change, processes of change, pros and cons of decisional balance, and self-efficacy. ${ }^{[18]}$ TTM defines behaviour change as a progressive process through a series of five stages: pre contemplation (unawareness of problem, not considering change), contemplation (considering change), preparation (intending to change), action (taking initial steps) and maintenance (sustaining the new behaviour). ${ }^{[19,20]}$

Ten processes of change are classified as experiential and behavioural processes. Experiential processes involve consciousness raising (learning new facts, ideas), environmental re evaluation (social reappraisal), social liberation (environmental opportunities), dramatic relief (emotional arousal), and self-re evaluation (self reappraisal). Behavioural processes include stimulus control (Removing reminders), helping relationship (supporting), counter conditioning(substituting), self-liberation (committing) and reinforcement management (rewarding). The third construct of the model is "decisional balance", which is defined as (pros) The benefits of changing and The costs of changing (cons) of behavior change from the individual's view. ${ }^{\text {[21] }}$ According to this model, change occurs when the benefits are greater than the costs. ${ }^{\text {[2] }}$ The fourth construct of the model is "self-efficacy", which refers to the individual's perceived confidence in the ability to perform a particular behavior successfully. ${ }^{[21]}$

\subsection{Significance of the study}

IDA affects the development of the nation by decreasing the cognitive and motor development of children and productivity of adults and prone to severe morbidity and mortality in pregnant women. ${ }^{[23]}$ Anaemia during pregnancy contributes to $20 \%$ of all maternal deaths. ${ }^{[1]}$ In pregnant women, severe cases of iron deficiency has poor outcome of neonates in the form of low birth weight, prematurity, intrauterine growth retardation, intrauterine death and birth asphyxia. ${ }^{[2]}$ IDA accounts for $75 \%$ of all types of anemia in the third world, affecting $30 \%$ of population. ${ }^{[25]}$ It has been further estimated that 90000 deaths in both sexes and all age groups are due to IDA alone. ${ }^{[26]}$ According to WHO Prevalence of anemia for pregnant women aged 15-49 years, 2011 is ranged from 20.0-39.9\% in Egypt. Also Egypt ranked in a moderate degree of public health significance of anaemia, based on blood hemoglobin concentration. ${ }^{[27]}$ 


\subsection{Aim of the study:}

The aim of this study was to evaluate diet behaviour of pregnant woman with iron deficiency anaemia before and after the implementation of educational intervention based trans-theoretical model of change. This aim achieved through:

- Assessing pregnant woman' knowledge and diet behaviour using construct of the trans-theoretical model to identify their needs.

- Designing and implementing an educational intervention based on trans-theoretical model according to pregnant women' needs.

- Evaluating the effect of an educational intervention on pregnant women' knowledge and diet behaviour using construct of the trans-theoretical model.

\subsection{Research hypothesis}

Knowledge and diet behaviour of pregnant women with iron deficiency anaemia will be improved after implementation of an educational intervention based trans-theoretical model of behaviour change.

\section{Subjects and Methods}

2.1. Research design: A quasi experimental design was used to test the study hypothesis.

2.2. Setting: This study was conducted at obstetrics and gynecology outpatient clinic of Benha teaching hospital, Benha city.

\subsection{Sample type and criteria:}

A purposive sample of 73 anemic pregnant women were recruited for the study and fulfilled the following inclusion criteria; woman having hemoglobin levels below $11 \mathrm{~g} / \mathrm{dl}$ in the $1^{\text {st }}$ trimester of pregnancy, Singleton pregnancy, free from obstetrical complication as (bleeding, gestational diabetes and pregnancy induced hypertension) or other chronic disorders affect pregnancy such as (heart disease, asthma or epilepsy), in pre-contemplation, contemplation and preparation stage of change and agreed to participate in the study.

\subsection{Sample Size}

According to Benha teaching hospital statistical center, 2014, flow rate of the anemic pregnant women were 730 women at the end of year 2014. Ten percent of flow rate (73 women) was selected. Therefore the sample size was 73 pregnant women.

2.5. Tools of data collection: Two tools were used to conduct the study:

2.5.1. First tool: Structured interviewing questionnaire was developed by the researchers in Arabic language after reviewing of related literature. It involved three main parts:

- Socio demographic data of the pregnant women such as; age, education, income, occupation, residence and telephone number.

- Medical and obstetric history of the pregnant women such as; gravidity, Inter-pregnancy interval and antenatal follow up

- Knowledge of the pregnant women regarding IDA. This part was used before and after implementation of the TTM (pre/ post-test format). It included eight open ended questions which include; definition, causes, signs and symptoms of IDA, effect of IDA on pregnant women and fetus, preventive measures of IDA, plant and animal foods rich in iron and importance of iron supplementation.

Scoring system of knowledge: A correct answer was scored "two", incomplete answer was scored "one" and the unknown or incorrect answer scored "zero". The total knowledge score was calculated by adding the scores for the correct answers. The total possible score ranged from 0 to 16 point. The higher scores reflect higher levels of knowledge about IDA.

2.5.2. Second tool: The TTM of behavior change questionnaire, it was developed, established and modified based on a comprehensive literature ${ }^{[21,28,29]}$, and translated to Arabic language. This part was used before and after implementation of the TTM (pre/ post-test format). This tool encompassed four main constructs of TTM.

i. Woman's stage of change related to diet behavior modification

The five-item stage of change was designed to assess woman's readiness for change. Participants selected one of five statements best representing their current intentions for diet behavior modification. The 5 items stages of change scored as a following [pre-contemplation $=1$, contemplation $=2$, preparation $=3$, action $=4$, maintenance $=5$ ].

\section{ii. The Self-efficacy scale regarding diet behavior modification}

Self-efficacy regarding diet behavior modification was assessed using a scale included 6-items. Pregnant women endorsed each item using a 3-point Likert scale. The scores were 1 for no confidence, 2 for somewhat confidence and 3 for confidence. While the maximum score of self-efficacy $=18$. 


\section{iii. Decisional balance scale related to diet behavior modification.}

Decisional balance (pros and cons) were assessed using 11 items, 5 pros to assess perceived benefits and 6 cons to assess barriers to follow health diet rich in iron. Pregnant women rated each item using a 3-point Likert scale. The scores of (pros) were 1 for disagree, 2 for somewhat and 3 for agree. While the scores of (cons) were 1 for agree, 2 for somewhat and 3 for disagree. Maximum score of pros $=15$ and cons $=18$.

iv. Processes of change related to diet behavior modification.

Experiential and behavioural processes of change were assessed by 10 elements, 5 for experiential processes which involve "consciousness raising, environmental re-evaluation, social liberation, dramatic relief, and self- re-evaluation". And 5 elements for behavioural processes which include "self-liberation, counter conditioning, stimulus control, reinforcement management and helping relationships". Each element of experiential and behavioural processes were assessed by 2 statements. The pregnant women indicated frequency of use for each process within the past month on a 3-point Likert- scale. The score were 1 for never, 2 for sometimes and 3 for always. Maximum score of each element $=6$. While the total score for experiential processes $=30$ and behavioural processes $=30$.

\subsubsection{Tools validity:}

The tools were reviewed for content validity by a jury of five experts in the field of community health nursing and obstetrics and woman health nursing to ascertain relevance and completeness.

\subsubsection{Tools Reliability:}

Reliability of tools was tested by using Cronbach's Alpha coefficient test, which revealed that the tools consisted of relatively homogenous items as showed by the moderate to high reliability of each tool. The internal consistency of knowledge was 0.78; Self-efficacy Scale was 0.85, pros was 0.86, cons was 0.75, experiential processes was 0.79 and behavioral processes 0.83 .

\subsection{Ethical considerations:}

Before data collection, the women were informed about the purpose of the study. They were given an opportunity to refuse or to participate in the study. Also they were assured that, their information would remain confidential and used only for the research purpose.

\subsection{Pilot study:}

A pilot study was carried out on $10 \%$ of the sample (8) pregnant women to assess the tools clarity and objectivity as well as estimation of the time needed to fill the questionnaire. The participants involved in the pilot were excluded from the study sample.

\subsection{Field work: (intervention construction)}

A written official approval to conduct this research was obtained from the Dean of faculty nursing to director of Benha teaching hospital. Other written official letter was taken and delivered to the director of obstetrics and gynaecology outpatient clinic, in order to obtain their agreement to conduct the study after explaining its purpose. The study was carried out through four main phases: assessment, planning, implementation, and evaluation. These phases were carried out from beginning of January 2015 to the end of August 2015, covering along a period of 8 months. The previous mentioned setting was visited by the researchers two days/week (Sunday and Thursday) from $9.00 \mathrm{am}$ to $12.00 \mathrm{pm}$ according to the schedule of obstetrics and gynaecology outpatient clinic.

\subsubsection{Assessment phase:}

The researchers interviewed the pregnant women after reviewing her medical record, ensure of her health status, explained the aim of the study, and asked for participation. Upon consent to participate, each pregnant woman was interviewed to assess general characteristics, knowledge regarding IDA, as well as TTM of behaviour change questionnaire to evaluate the participants' stages of change, self-efficacy, decisional balance and process of change. The data obtained during this phase constituted the baseline for further comparisons to evaluate the effect of TTM on diet behaviour modification. Average time for the completion of interviewing questionnaire (20-25 minutes). A number of interviewed women / week ranged from 4-5 women. The questionnaire is filled by the researcher during waiting time of the women during their antenatal visits.

\subsubsection{Planning phase:}

Based on the identified stage of change of each pregnant woman, and in view of the related literature. The intervention was designed by the researchers based on the participants' stages of change and level of difficulty in a form of printed Arabic booklet to satisfy the participants' deficit knowledge and strategies for diet behaviour modification. Women are classified into two groups according to previously identified stage of change as follows A) women at contemplation stage B) preparation stage. A booklet was designed specifically for women, in simple Arabic language to suit their level of understanding. It instructs mothers about stages of change so they can stage themselves and then provides information appropriate to the stages of change. Education was provided related to diet modification at the contemplation and preparation stages. It include the significance of IDA as cause of maternal mortality, definition of IDA, causes and risk factors for IDA, 
complications of IDA for the woman and the fetus, preventive strategies of IDA, medical treatment of IDA, plant and animal food sources high in iron, food sources high in vitamin C, and practical strategies for diet modification for the pregnant women at the contemplation and preparation stage.

\subsubsection{Implementation phase}

During implementation of the intervention programme applied TTM constructs by using stages of change, decisional balance, self-efficacy and process of change related to diet modification. Knowledge has been suggested to affect individuals' perceptions and influence behaviour, and was also included as a determinant of change. The intervention focused on providing appropriate strategies based on women' motivation to change. In addition to inducing changes in motivation and determinants of change using stagetargeted intervention. The researchers implemented the TTM of change-based behavioural intervention and gave women stage-matched intervention materials with explanation for them. The researchers explained the educational materials and guided mothers to focus on the part of the booklet that related to their own stages of change. According to visits' time schedule of participants, they were interviewed in a private room at outpatient clinic. The intervention involved two sessions which conducted to a small group (4-5) of the pregnant women. The duration of each session lasted from half an hour to one hour including periods of discussion according to their achievement and feedback. At the beginning of the first session an orientation to the intervention and its aims took place. Feedback was given in the beginning of each session about the previous one. Different teaching strategies were used such as lectures, group discussions, critical thinking and problem solving. Supportive tools that function as stimulus control to support desired changes include stickers and flyers that reinforce the concepts of the intervention and emphasizing the effects of IDA on mother and foetus.

\subsubsection{Evaluation phase}

Evaluation was applied by comparing knowledge and behaviour change regarding diet modification before and after implementation of TTM based intervention. This was done through reusing the same tools after three months in post-test to evaluate the effect of the implemented intervention.

\subsection{Statistical analysis:}

Data analysis was performed using Statistical Package for Social Sciences (SPSS version 20) Descriptive statistics were applied (e.g., frequency, percentages, mean, and standard deviation). Test of significance (paired t test, Fisher's Exact Test and chi-square test ) was applied to test the study hypothesis. Correlation coefficient was calculated between TTM construct and total knowledge and stage of diet behaviour change. A statistically significant difference was considered at $\mathrm{p}$-value $\leq .05$, and a highly statistically significant difference was considered at $\mathrm{p}$-value $\leq .001$, while the $\mathrm{p}$-value $>.05$ indicates non-significant results.

\section{Results}

Table (1): Represents socio-demographic characteristics of the studied subjects. It was clear that $49.3 \%$ of the pregnant women were aged from 30-<35 years, with a mean age 29.06 \pm 7.28 years. Regarding pregnant women' educational qualification, $37.0 \%$ of them had secondary education. Furthermore, $57.5 \%$ of them were housewives. As regards their income, $69.9 \%$ of women reported insufficient monthly income. In addition, $68.5 \%$ of the women were rural areas residence.

Table (2): Displays that, $53.4 \%$ of the pregnant women were multi gravida. Furthermore, $32.9 \%$ of them had a pervious history of anaemia before pregnancy. Moreover, 53.9\% of the women had 1-3years regarding interpregnancy interval. In addition $82.2 \%$ of the woman reported regular antenatal follow up and $61.6 \%$ of them were taking iron supplementation in a regular basis.

Table (3): Illustrates that, there were highly statistically significant differences $(\mathrm{P}<.001)$ before and after the intervention in relation to the stages of change for dietary behavior modification. While $50.7 \%$ of the studied pregnant women were at the contemplation stage before the intervention, while after the intervention $53.4 \%$ of them were at the action stage.

Table (4): Displays that there were highly statistically significant differences $(\mathrm{P}<.001)$ before and after the intervention in relation to women' knowledge about definition, causes, signs and symptoms of IDA as well as effect of IDA on pregnant women and fetus, preventive measures of IDA, plant and animal foods rich in iron, and importance of iron supplementation.

Table (5): Shows that the differences between pre and post intervention in all items related to self-efficacy toward diet behavior modification were highly statistically significant $(\mathrm{P}<.001)$.

Table (6): Demonstrates that the decisional balance pros and cons were significantly different $(\mathrm{P}<.001)$ between before and after the intervention based TTM.

Table (7): Clarifies that, there were highly statistically significant differences $(\mathrm{P}<.001)$ before and after intervention based TTM in relation to experiential and behavioural processes of change (environmental reevaluation, dramatic relief, self-re-evaluation, self-liberation, counter-conditioning, stimulus control, reinforcement management and helping relationships). Also statistically significant differences $(\mathrm{P}<.05)$ were found in relation to consciousness raising and social liberation. 
Table (8): Reflects that, there were general improvements $(\mathrm{P}<.001)$ in all TTM construct include (self-efficacy, pros, cons and experiential and behavioural processes) and total knowledge scores after the intervention based TTM as compared to before.

Table (9): Illustrates that, there were a positive, highly statistically significant correlation $(\mathrm{P} \leq .01)$ between studied pregnant women' total knowledge score and their stages of diet behavior change before and after the intervention. As well as between studied pregnant women' scores of self-efficacy, pros and experiential and behavioural processes and their stage of diet behavior change. On the other hand there was a negative, highly statistically significant correlation $(\mathrm{P} \leq .01)$ between the score of cones and the stage of diet behavior change before and after the intervention.

Figure (1): Displays that, $94.5 \%$ of the studied pregnant women who progressed in stages of change after intervention based TTM. Only $5.5 \%$ of them remained in the same stages (stationary).

Figure (2): Demonstrates the level of anemia among the studied pregnant women before and after intervention. It was clear that $24.7 \%$ of the pregnant women became free from anemia after intervention based TTM, only $2.7 \%$ of them still had severe anemia. Moreover, there was statistically significant difference $(\mathrm{P}<.05)$ before and after intervention regarding to the level of anemia.

Table (1) Distribution of the study subjects according to their socio-demographic characteristics. $(\mathrm{n}=73)$

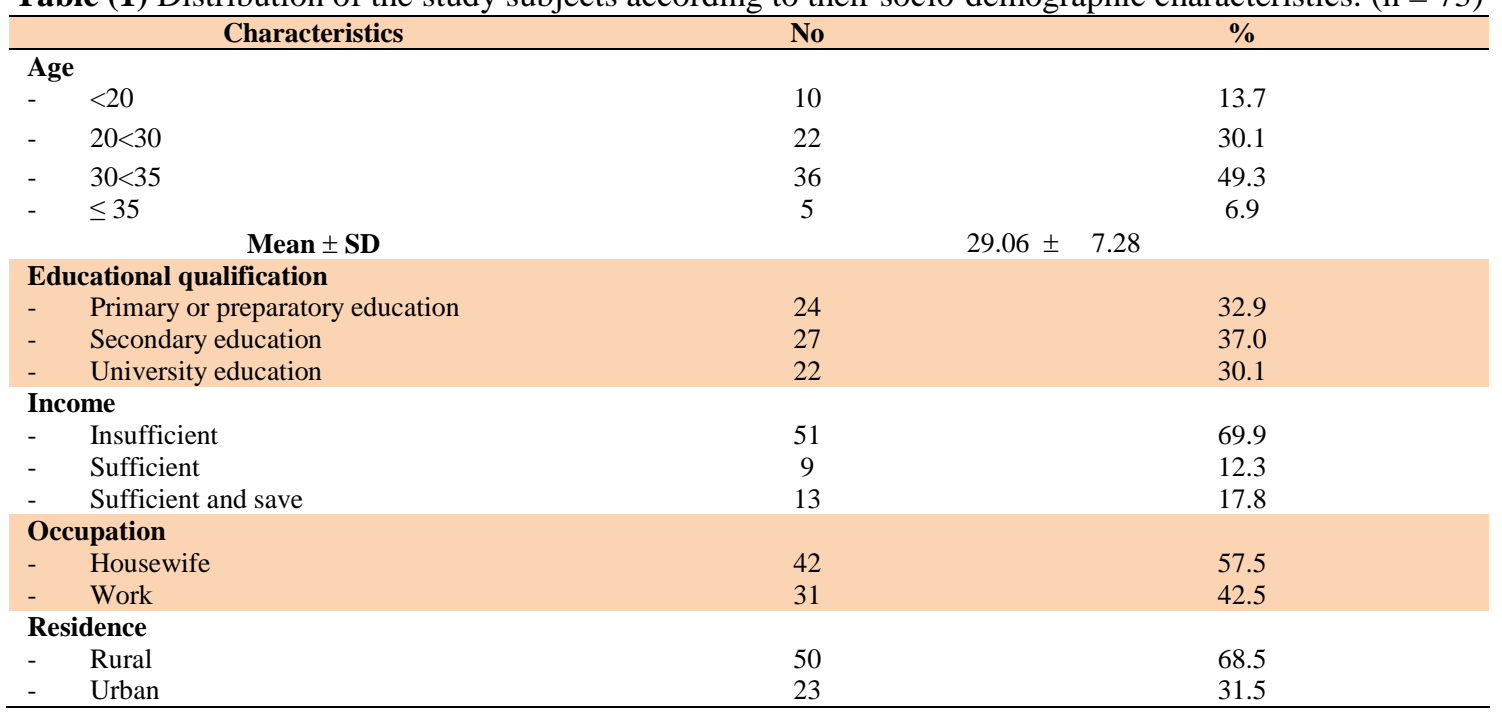

Table (2) Distribution of the study subjects according to their medical and obstetric history. $(\mathrm{n}=73)$

\begin{tabular}{|c|c|c|}
\hline Characteristics & No & $\%$ \\
\hline \multicolumn{3}{|l|}{ Gravidity } \\
\hline - $\quad$ Multi gravida & 39 & 53.4 \\
\hline Prim gravida & 34 & 46.6 \\
\hline \multicolumn{3}{|c|}{ History of Anemia before pregnancy } \\
\hline Yes & 24 & 32.9 \\
\hline No & 49 & 67.1 \\
\hline \multicolumn{3}{|l|}{ Inter-pregnancy interval $(n=39)$} \\
\hline - > lyear & 7 & 17.9 \\
\hline - 1-3years & 21 & 53.9 \\
\hline - $\quad>3$ years & 11 & 28.2 \\
\hline \multicolumn{3}{|l|}{ Antenatal follow up } \\
\hline - $\quad$ Regular & 60 & 82.2 \\
\hline Irregular & 13 & 17.8 \\
\hline \multicolumn{3}{|l|}{ Taking iron supplementation } \\
\hline - Yes & 45 & 61.6 \\
\hline$-\quad$ No & 28 & 38.4 \\
\hline
\end{tabular}

Table (3) Classification of stages of change for dietary behavior modification among the study subjects pre and post intervention $(n=73)$.

\begin{tabular}{lcccccc}
\multicolumn{1}{c}{ Stages of change } & \multicolumn{2}{c}{ Pre-intervention } & \multicolumn{2}{c}{ Post-intervention } & FET & P value \\
Pre contemplation & No & \% & No & \% & 61.378 & $<.001^{* *}$ \\
Contemplation & - & - & - & - & \\
Preparation & 37 & 50.7 & 4 & - & \\
Action & 36 & 49.3 & - & 53.4 & \\
Maintenance & - & - & 39 & 41.1 \\
\hline \multicolumn{1}{c}{ FET $=$ Fisher's Exact Test } & - & - & 30 & $77 \mid$ Page
\end{tabular}


Diet Behavior Modification of Pregnant Woman with Iron...

Table (4): Distribution of the studied subjects according to their knowledge toward iron deficiency anemia $(\mathrm{n}=73)$.

\begin{tabular}{|c|c|c|c|c|c|c|c|c|c|c|c|c|c|c|}
\hline \multirow{3}{*}{ Items } & \multicolumn{6}{|c|}{ Pre-intervention } & \multicolumn{6}{|c|}{ Post-intervention } & \multirow[t]{3}{*}{ FET $/ \chi^{2}$} & \multirow[t]{3}{*}{ P value } \\
\hline & \multicolumn{2}{|c|}{$\begin{array}{l}\text { Correct } \\
\text { answer }\end{array}$} & \multicolumn{2}{|c|}{$\begin{array}{c}\text { Incomplete } \\
\text { answer }\end{array}$} & \multicolumn{2}{|c|}{$\begin{array}{l}\text { Don't } \\
\text { know }\end{array}$} & \multicolumn{2}{|c|}{$\begin{array}{l}\text { Correct } \\
\text { answer }\end{array}$} & \multicolumn{2}{|c|}{$\begin{array}{c}\text { Incomplete } \\
\text { answer }\end{array}$} & \multicolumn{2}{|c|}{$\begin{array}{l}\text { Don't } \\
\text { know }\end{array}$} & & \\
\hline & No & $\%$ & No & $\%$ & No & $\%$ & No & $\%$ & No & $\%$ & No & $\%$ & & \\
\hline Definition of IDA & 13 & 17.8 & 18 & 24.7 & 42 & 57.5 & 18 & 24.7 & 41 & 56.2 & 14 & 19.2 & 80.715 & $<.001 * *$ \\
\hline Causes of IDA & 3 & 4.1 & 33 & 45.2 & 37 & 50.7 & 37 & 50.7 & 22 & 30.1 & 14 & 19.2 & 40.875 & $<.001 * *$ \\
\hline Signs and symptoms of IDA. & 9 & 12.3 & 38 & 52.1 & 26 & 35.6 & 51 & 69.9 & 22 & 30.1 & 0 & 0.0 & 42.128 & $<.001 * *$ \\
\hline Effect of IDA on pregnant women & 0 & 0.0 & 37 & 50.7 & 36 & 49.3 & 32 & 43.8 & 41 & 56.2 & 0 & 0.0 & 45.601 & $<.001 * *$ \\
\hline Effect of IDA on the fetus & 4 & 5.5 & 18 & 24.7 & 51 & 69.9 & 45 & 61.6 & 13 & 17.8 & 15 & 20.5 & 44.725 & $<.001 * *$ \\
\hline Preventive measures of IDA & 23 & 31.5 & 13 & 17.8 & 37 & 50.7 & 51 & 69.9 & 22 & 30.1 & 0 & 0.0 & 30.639 & $<.001 * *$ \\
\hline Plant and animal foods rich in iron & 9 & 12.3 & 49 & 67.1 & 15 & 20.5 & 36 & 49.3 & 26 & 35.6 & 11 & 15.1 & 61.573 & $<.001^{* *}$ \\
\hline Importance of iron supplementation & 13 & 17.8 & 31 & 42.5 & 29 & 39.7 & 22 & 30.1 & 48 & 65.8 & 3 & 4.1 & 43.524 & $<.001 * *$ \\
\hline
\end{tabular}
FET = Fisher's Exact Test

*** Highly statistically significant difference at $\mathrm{P} \leq .001$

Table (5): Distribution of the studied subjects according to their self-efficacy toward diet behavior modification $(\mathrm{n}=73)$

\begin{tabular}{|c|c|c|c|c|c|c|c|c|c|c|c|c|c|c|c|}
\hline \multirow{3}{*}{\multicolumn{2}{|c|}{$\begin{array}{l}\text { Study period } \\
\text { Items }\end{array}$}} & \multicolumn{6}{|c|}{ Pre-intervention } & \multicolumn{6}{|c|}{ Post-intervention } & \multirow[t]{3}{*}{ FET $/ \chi^{2}$} & \multirow[t]{3}{*}{ P value } \\
\hline & & \multicolumn{2}{|c|}{$\begin{array}{l}\text { Not } \\
\text { confident }\end{array}$} & \multicolumn{2}{|c|}{ Somewhat } & \multicolumn{2}{|c|}{ Confident } & \multicolumn{2}{|c|}{$\begin{array}{l}\text { Not } \\
\text { confident }\end{array}$} & \multicolumn{2}{|c|}{ Somewhat } & \multicolumn{2}{|c|}{ Confident } & & \\
\hline & & No & $\%$ & No & $\%$ & No & $\%$ & No & $\%$ & No & $\%$ & No & $\%$ & & \\
\hline 1. & $\begin{array}{l}\text { When I am in a hurry, I prepare meals } \\
\text { rich with plant and animal foods high } \\
\text { in iron. }\end{array}$ & 36 & 49.3 & 22 & 30.1 & 15 & 20.5 & 14 & 19.2 & 13 & 17.8 & 46 & 63.0 & 44.038 & $<.001 * *$ \\
\hline 2. & $\begin{array}{l}\text { When I have the chance to choose, I } \\
\text { can eat the plant and animal foods high } \\
\text { in iron. }\end{array}$ & 42 & 57.5 & 27 & 37.0 & 4 & 5.5 & 3 & 4.1 & 48 & 65.8 & 22 & 30.1 & 35.825 & $<.001 * *$ \\
\hline 3. & $\begin{array}{l}\text { I can shop for a variety plant and } \\
\text { animal foods high in iron }\end{array}$ & 27 & 37.0 & 24 & 32.9 & 22 & 30.1 & 2 & 2.7 & 25 & 34.2 & 46 & 63.0 & 72.006 & $<.001 * *$ \\
\hline 4. & $\begin{array}{l}\text { When I feeling restless or bored, I can } \\
\text { eat the plant and animal foods high in } \\
\text { iron. }\end{array}$ & 54 & 74.0 & 4 & 5.5 & 15 & 20.5 & 15 & 20.5 & 32 & 43.8 & 26 & 35.6 & 28.608 & $<.001 * *$ \\
\hline 5. & $\begin{array}{l}\text { When I celebrating with others, I can } \\
\text { eat the plant and animal foods high in } \\
\text { iron. }\end{array}$ & 49 & 67.1 & 24 & 32.9 & 0 & 0 & 18 & 24.7 & 27 & 37.0 & 28 & 38.4 & 30.373 & $<.001 * *$ \\
\hline 6. & $\begin{array}{l}\text { When I eat outside home, can eat the } \\
\text { plant and animal foods high in iron. }\end{array}$ & 36 & 49.3 & 37 & 50.7 & 0 & 0 & 17 & 23.3 & 37 & 50.7 & 19 & 26.0 & 27.433 & $<.001 * *$ \\
\hline
\end{tabular}

Table (6): Distribution of the studied subjects according to their decisional balance toward diet behavior modification $(\mathrm{n}=$ 73).

\begin{tabular}{|c|c|c|c|c|c|c|c|c|c|c|c|c|c|c|c|}
\hline \multirow{3}{*}{\multicolumn{2}{|c|}{$\begin{array}{l}\text { Study period } \\
\text { Items }\end{array}$}} & \multicolumn{6}{|c|}{ Pre-intervention } & \multicolumn{6}{|c|}{ Post-intervention } & \multirow[t]{3}{*}{ FET $/ \chi 2$} & \multirow[t]{3}{*}{ P value } \\
\hline & & \multicolumn{2}{|c|}{ Agree } & \multicolumn{2}{|c|}{ Somewhat } & \multicolumn{2}{|c|}{$\begin{array}{l}\text { Don't } \\
\text { agree }\end{array}$} & \multicolumn{2}{|c|}{ Agree } & \multicolumn{2}{|c|}{ Somewhat } & \multicolumn{2}{|c|}{$\begin{array}{l}\text { Don't } \\
\text { agree }\end{array}$} & & \\
\hline & & No & $\%$ & No & $\%$ & No & $\%$ & No & $\%$ & No & $\%$ & No & $\%$ & & \\
\hline \multicolumn{16}{|c|}{ Pros } \\
\hline 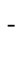 & $\begin{array}{l}\text { It is good for my health if I eat the } \\
\text { foods high in iron }\end{array}$ & 12 & 16.4 & 61 & 83.6 & 0 & 0 & 31 & 42.5 & 42 & 57.5 & 0 & 0 & 17.744 & $<.001 * *$ \\
\hline- & $\begin{array}{l}\text { Eating foods high in iron will improve } \\
\text { my health status }\end{array}$ & 27 & 37.0 & 46 & 63.0 & 0 & 0 & 45 & 61.6 & 28 & 38.4 & 0 & 0 & 26.661 & $<.001 * *$ \\
\hline - & $\begin{array}{l}\text { Eating foods high in iron will prevent } \\
\text { the complications arising during and } \\
\text { after labour }\end{array}$ & 29 & 39.7 & 31 & 42.5 & 13 & 17.8 & 60 & 82.2 & 13 & 17.8 & 0 & 0 & 43.974 & $<.001 * *$ \\
\hline - & $\begin{array}{l}\text { Eating foods high in iron will be good } \\
\text { for my foetus }\end{array}$ & 29 & 39.7 & 34 & 46.6 & 10 & 13.7 & 35 & 47.9 & 38 & 52.1 & 0 & 0 & 18.605 & $<.001 * *$ \\
\hline - & $\begin{array}{l}\text { Eating foods high in iron would help } \\
\text { me maintain my weight. }\end{array}$ & 36 & 49.3 & 28 & 38.4 & 9 & 12.3 & 42 & 57.5 & 31 & 42.5 & 0 & 0 & 16.868 & $<.001 * *$ \\
\hline \multicolumn{16}{|c|}{ Cons } \\
\hline - & $\begin{array}{l}\text { It is difficult to find the foods high in } \\
\text { iron that I like. }\end{array}$ & 28 & 38.4 & 36 & 49.3 & 9 & 12.3 & 15 & 20.5 & 22 & 30.1 & 36 & 49.3 & 42.150 & $<.001 * *$ \\
\hline - & $\begin{array}{l}\text { I don't have time to shop the foods } \\
\text { high in iron }\end{array}$ & 15 & 20.5 & 44 & 60.3 & 14 & 19.2 & 8 & 11.0 & 40 & 54.8 & 25 & 34.2 & 66.700 & $<.001 * *$ \\
\hline - & $\begin{array}{l}\text { I worry about the safety of chemicals } \\
\text { used in plant foods high in iron. }\end{array}$ & 26 & 35.6 & 32 & 43.8 & 15 & 20.5 & 13 & 17.8 & 14 & 19.2 & 46 & 63.0 & 45.625 & $<.001 * *$ \\
\hline - & $\begin{array}{l}\text { It is expensive to purchase foods high } \\
\text { in iron }\end{array}$ & 37 & 50.7 & 28 & 38.4 & 8 & 11.0 & 0 & 0 & 28 & 38.4 & 45 & 61.6 & 44.195 & $<.001 * *$ \\
\hline - & $\begin{array}{l}\text { It would be too confusing for me to } \\
\text { follow all the recommendations about } \\
\text { eating foods high in iron }\end{array}$ & 40 & 54.8 & 24 & 32.9 & 9 & 12.3 & 6 & 8.2 & 26 & 35.6 & 41 & 56.2 & 10.994 & $<.001 * *$ \\
\hline - & $\begin{array}{l}\text { I don't think I know enough about } \\
\text { foods high in iron }\end{array}$ & 45 & 61.6 & 23 & 31.5 & 5 & 6.8 & 14 & 19.2 & 46 & 63.0 & 13 & 17.8 & 31.054 & $<.001 * *$ \\
\hline
\end{tabular}
FET $=$ Fisher's Exact Test ** Highly statistically significant difference at $\mathrm{P} \leq .001$ 
Table (7): Mean scores of experiential and behavioural processes of change toward diet behavior modification among the study subjects pre and post intervention $(n=73)$.

\begin{tabular}{|c|c|c|c|c|c|c|}
\hline & & $\begin{array}{l}\text { Maximum } \\
\text { score }\end{array}$ & Pre-intervention & Post-intervention & Paired $t$ test & P value \\
\hline \multicolumn{7}{|c|}{ Experiential processes } \\
\hline 1. & Consciousness raising & 6 & $4.16 \pm 1.14$ & $4.58 \pm 1.11$ & 2.189 & $<.05 *$ \\
\hline 2. & Environmental re-evaluation & 6 & $2.73 \pm 0.97$ & $4.50 \pm 1.54$ & 11.025 & $<.001 * *$ \\
\hline 3. & Social liberation & 6 & $4.28 \pm 0.93$ & $4.58 \pm 0.92$ & 2.034 & $<.05^{*}$ \\
\hline 4. & Dramatic relief & 6 & $4.05 \pm 1.10$ & $5.21 \pm 0.88$ & 11.703 & $<.001 * *$ \\
\hline 5. & Self-re-evaluation & 6 & $3.27 \pm 0.98$ & $3.89 \pm 1.27$ & 7.526 & $<.001 * *$ \\
\hline \multicolumn{7}{|c|}{ Behavioural processes } \\
\hline 6. & Self-liberation & 6 & $3.53 \pm 1.00$ & $4.90 \pm 0.71$ & 12.511 & $<.001 * *$ \\
\hline 7. & Counter-conditioning & 6 & $4.20 \pm 0.95$ & $5.24 \pm 0.66$ & 10.796 & $<.001 * *$ \\
\hline 8. & Stimulus control & 6 & $3.95 \pm 1.20$ & $5.15 \pm 1.27$ & 11.413 & $<.001 * *$ \\
\hline 9. & Reinforcement management & 6 & $4.42 \pm 0.81$ & $5.45 \pm 1.00$ & 9.785 & $<.001 * *$ \\
\hline 10. & Helping relationships & 6 & $4.28 \pm 1.09$ & $4.94 \pm 1.02$ & 4.905 & $<.001 * *$ \\
\hline
\end{tabular}

Table (8) Mean differences of subtotal TTM construct and total knowledge scores of the study subjects between

\begin{tabular}{|c|c|c|c|c|c|}
\hline & $\begin{array}{l}\text { Maximum } \\
\text { score }\end{array}$ & Pre-intervention & Post-intervention & $\begin{array}{l}\text { Paired } t \\
\text { test }\end{array}$ & $P$ value \\
\hline \multicolumn{6}{|l|}{ TTM constructs score } \\
\hline - Self-efficacy & 18 & $9.12 \pm 2.22$ & $14.28 \pm 2.39$ & 26.473 & $<.001 * *$ \\
\hline - Decisional balance (Pros) & 15 & $11.30 \pm 1.78$ & $12.86 \pm 1.44$ & 8.347 & $<.001 * *$ \\
\hline - Decisional balance (Cons) & 18 & $13.79 \pm 1.43$ & $10.11 \pm 2.38$ & 15.010 & $<.001 * *$ \\
\hline - Experiential processes & 30 & $18.69 \pm 2.33$ & $23.41 \pm 3.39$ & 11.753 & $<.001 * *$ \\
\hline - Behavioral processes & 30 & $20.53 \pm 4.13$ & $25.69 \pm 3.57$ & 16.232 & $<.001 * *$ \\
\hline Total knowledge score & 16 & $5.27 \pm 2.53$ & $11.19 \pm 2.40$ & 40.629 & $<.001 * *$ \\
\hline
\end{tabular}

**A highly statistical significant difference $(\mathrm{P} \leq .001)$

Table (9): Correlation coefficient between study subjects' subtotal scores of TTM constructs and total knowledge score and their stage of nutritional behaviour change before and after intervention $(\mathrm{n}=73)$.

\begin{tabular}{|c|c|c|c|c|c|c|}
\hline \multicolumn{3}{|c|}{ Variables } & \multicolumn{4}{|c|}{ The stages of diet behavior change } \\
\hline & & & \multicolumn{2}{|c|}{ Pre-intervention } & \multicolumn{2}{|c|}{ Post-intervention } \\
\hline & & & $\boldsymbol{r}$ & $P$ & $r$ & $\boldsymbol{P}$ \\
\hline \multicolumn{7}{|c|}{ TTM construct } \\
\hline \multirow{2}{*}{\multicolumn{2}{|c|}{ - $\quad$ Self-efficacy }} & Pre-intervention & 0.638 & $<.01 * *$ & & \\
\hline & & Post-intervention & & & 0.609 & $<.01 * *$ \\
\hline \multirow[t]{2}{*}{-} & Decisional balance_(pros) & Pre-intervention & 0.701 & $<.01 * *$ & & \\
\hline & & Post-intervention & & & 0.585 & $<.01 * *$ \\
\hline \multirow[t]{2}{*}{ - } & Decisional balance_(Cons) & Pre-intervention & -0.566 & $<.01 * *$ & & \\
\hline & & Post-intervention & & & -0.631 & $<.01 * *$ \\
\hline \multirow[t]{2}{*}{-} & Experiential processes & Pre-intervention & 0.484 & $<.01 * *$ & & \\
\hline & & Post-intervention & & & 0.602 & $<.01 * *$ \\
\hline \multirow[t]{2}{*}{-} & Behavioral processes & Pre-intervention & 0.506 & $<.01 * *$ & & \\
\hline & & Post-intervention & & & 0.622 & $<.01 * *$ \\
\hline \multirow[t]{2}{*}{-} & Total knowledge score & Pre-intervention & 0.742 & $<.01 * *$ & & \\
\hline & & Post-intervention & & & 0.568 & $<.01 * *$ \\
\hline
\end{tabular}

***Correlation is highly statistically significant at $\mathrm{P} \leq .01$ 


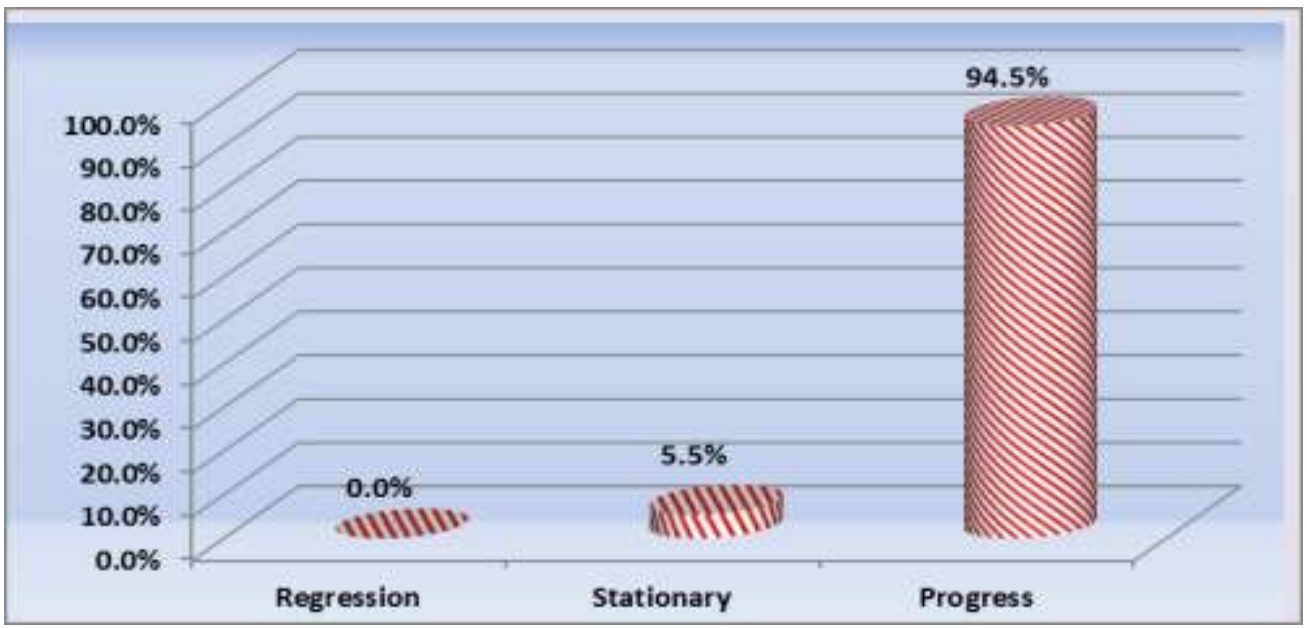

Fig. (1) Stage movement from pre- intervention to post- intervention $(n=73)$

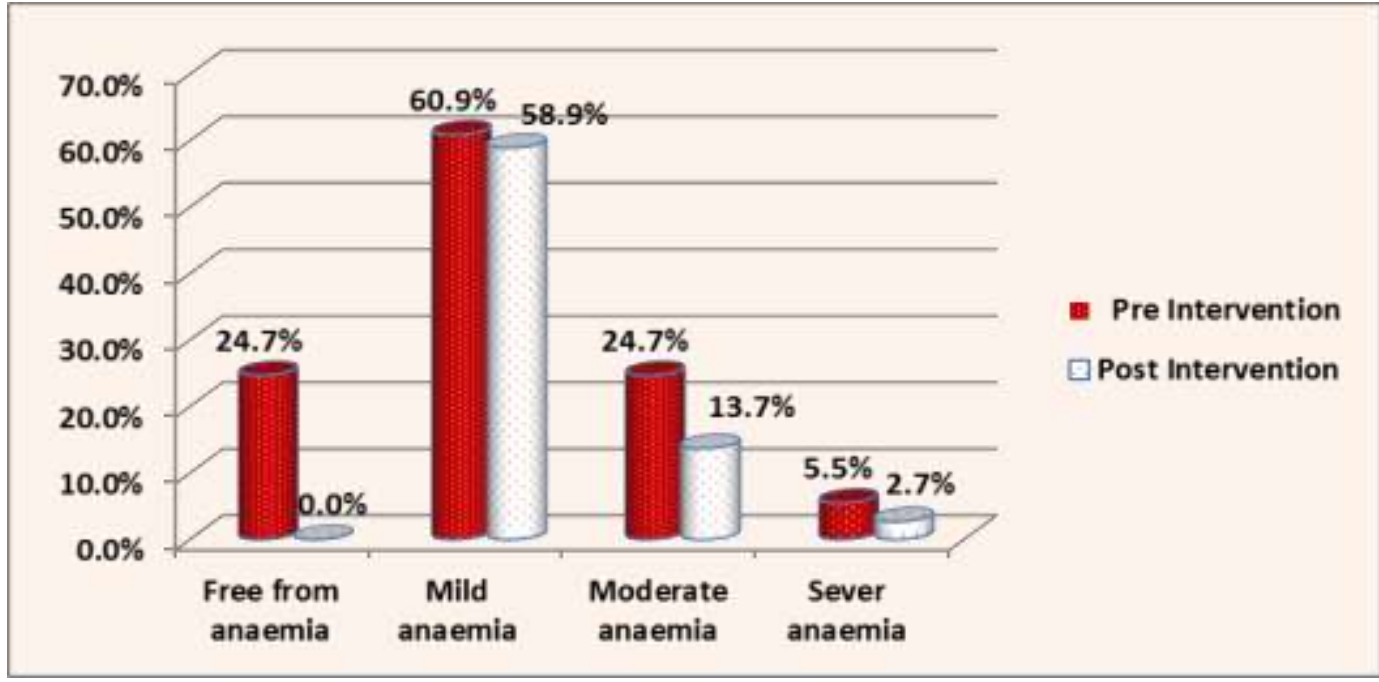

(Fisher's Exact Test $=17.987 \quad$ P $<0.05^{*}$ )

Figure (2 ) Distribution of the studied subjects according to their level of anemia pre and post- intervention $(n=73)$.

\section{Discussion}

Anemia is the most common disorder of the blood, affecting about a quarter of the people globally. ${ }^{[30]}$ IDA is a major cause of morbidity and mortality of pregnant women and increases the risks of foetal, neonatal and infant mortality. ${ }^{[31]}$ Nutritional education, with special emphasis on strategies based on locally available food stuffs to improve the dietary intake of proteins and iron is important during pregnancy. ${ }^{[32]}$ Behavioral models and theories should be used to help individuals better understand eating behaviors. The TTM has been presented as an integrative and comprehensive model that provides the opportunity of making the decision of an appropriate treatment plan for the individual. Also it has demonstrated positive impacts on individuals with different risk behaviors related to non-communicable diseases. ${ }^{[21,33]}$ So the present study was conducted to evaluate diet behavior of pregnant woman with IDA before and after the implementation of intervention strategies incorporating the TTM of Change.

Sociodemographic characteristics can play a major role in determining anemia among pregnant woman. $^{[34]}$ As regard socio-demographic characteristic of the studied pregnant women, it was found that nearly half of the anemic pregnant women were aged from 30-<35 years with a mean age 29.06 \pm 7.28 years. This might be related to the effect of parity on increasing maternal age. This finding is consistent with a study done in Saudi Arabia by Yakout, et al. ${ }^{[35]}$ about "the effect of iron supplementation and nutritional education among group of anemic pregnant women on their prenatal outcome", found that the majority of their studied subjects was 25 to less than 35 years.

On the other hand Nwizu et al. and Biswas, and Baruah ${ }^{[36,37]}$ reported different results. Where the former had studied "socio-demographic and maternal factors in anemia in pregnancy at booking in northern Nigeria", showed that the percentage of pregnant women with anemia was not inversely related to their age. The latter had studied "maternal anemia associated with socio-demographic factors among pregnant women" 
reported that most of the anemic pregnant women were in the age group 20-24years. The difference between our study findings and the latter group studies might be related to the difference in the selection criteria.

The current study has shown that more than two thirds of anemic pregnant women reported insufficient monthly income. These findings came in the same line with study of Sharma et al. ${ }^{[38]}$ about "prevalence of anemia and socio-demographic factors associated with anemia among pregnant women attending antenatal Hospital in Jaipur City, India", reported that low economic status of women considered the main determinates that contribute to the problem of anemia during pregnancy. Also Mohammed ${ }^{[39]}$ who conducted a study to determine "the prevalence of anemia and associated factors among pregnant women in Northeast Ethiopia" and found that monthly income was significantly associated with IDA during pregnancy.

It's obvious from current study that the pregnant women with IDA who living in the urban areas was lower than that of pregnant women living in rural areas. This could be due to the reason that pregnant women from rural areas might have economic factors, lack of knowledge about healthy nutrition during pregnancy, and inaccessibility to health care facilities. This is consistent with Kraja et al. ${ }^{[40]}$ who conducted a study about "iron deficiency anaemia among pregnant women in Shokodra District ". He found also that the prevalence of anemia among women living in the city was lower than that of women living in rural areas. Also Gebre and Mulugeta ${ }^{[41]}$ who had studied the "prevalence of anemia and associated factors among pregnant women in Northern Ethiopia" documented that the prevalence of anemia was higher among pregnant women residents of rural areas as compared to pregnant women residents of urban areas.

Obstetric and medical history of a pregnant woman play great role in determining hemoglobin status through increasing iron requirement or reduction of its storage. The present study displayed that, more than half of the pregnant women were multi gravid and were1-3years regarding birth spacing. This result is in congruent with Salahat and Ibrahim ${ }^{[42]}$ who had studied the prevalence of anemia among Jordanian pregnant women, found the prevalence of anemia higher in Multipara women than among primigravida women. Moreover, Okube, et al. ${ }^{[43]}$ who had studied "anaemia among pregnant women attending antenatal clinic in the second and third trimesters at Pumwani Maternity Hospital, Kenya". He found that more than half of the pregnant women were multi gravid and more than three quarters of them their inter-pregnancy interval was $>2$ years. The findings of Selim et al. ${ }^{[4]}$ who had studied "the prevalence iron deficiency anemia in addition to the associated factors among Arab pregnant women in Qatar" supported our study findings .He stated that the prevalence of IDA increased with increasing parity. The relation between IDA and repeated pregnancies and deliveries has been attributed to the cumulative demands on iron stores. ${ }^{[4]}$

The current study had been evaluated the knowledge of the studied pregnant women regarding IDA before and after intervention based TTM, therefore, the findings of the current study pointed out that the studied pregnant women had deficient knowledge below the average level about IDA before the educational intervention based TTM. Their low scores of knowledge may be attributed to that most of the studied women had preparatory and secondary education, only less than one third of them had university education. These findings agree with at least three other researches. First, Ghimire and Pandey ${ }^{[45]}$ who had assessed "the knowledge and practice of mothers regarding the prevention of anemia during pregnancy in Tribhuvan University Teaching Hospital". He found that the mothers who delivered at University hospital didn't have adequate knowledge regarding the prevention of anemia and regarding sources of iron containing foods. Second Shanthini and Nivedita ${ }^{[46]}$ who studied "knowledge, attitude and practices of pregnant women regarding IDA and its impact on their hemoglobin levels". His study indicated the lack of knowledge regarding anemia, iron rich foods and the importance of iron supplementation during pregnancy. Third Balasubramanian et al. ${ }^{[47]}$ who had evaluated "the awareness of anemia among pregnant women and impact of demographic factors on their hemoglobin status", found that there was lack of knowledge among antenatal mothers regarding anemia and its complications.

Furthermore, The current study results showed highly significant improvement $(\mathrm{P}<.001)$ in the pregnant women' knowledge regarding definition, causes, signs and symptoms of IDA as well as effect of IDA on pregnant women and fetus, preventive measures of IDA, plant and animal foods rich in iron, and importance of iron supplementation. The possible explanation for this improvement of knowledge post intervention might be reflect the impact of educational intervention based TTM on enhancing knowledge and awareness accretion. In this regard Abd ElHameed et al. ${ }^{[48]}$ who had studied the "effect of nutritional educational guideline among pregnant women with iron deficiency anemia at rural areas in Kalyobia governorate", found a highly significant improvement $(\mathrm{P}<.001)$ in the pregnant women' knowledge regarding all items related to IDA such as meaning, causes, sign and symptoms, prevention of IDA after intervention of nutritional educational guideline. In addition, Khoramabadi et al. ${ }^{[49]}$ concluded that educational interventions based theories and health promotion models can be effective in enhancing knowledge, better awareness of risks, decreasing barriers to healthy behaviour and ultimately, improving women's health and nutritional behaviour during pregnancy.

The current study describes stages of change in dietary behavior modification among the studied pregnant women. The findings showed highly statistically significant differences $(\mathrm{P}<.001)$ before and after the 
intervention in relation to the stages of change for dietary behavior modification. More than half of the studied pregnant women were at the contemplation stage before the intervention, while after the intervention more than half of them were at the action stage. These findings suggest that the TTM-based intervention helps to maintain and develop the stage of behavior change and demonstrates program effectiveness. The effectiveness of nursing educational intervention may be enhanced by applying effective components of the theory to educational materials as TTM. Huang et al. ${ }^{[50]}$

This finding is in the same line with Huang et al. and Holmen et al. ${ }^{[51,52]}$ Where the former, had applied "trans-theoretical model among pregnant women in Taiwan", showed statistically significant difference between the pregnant women in the study and control groups regarding the stages of change after intervention. Where the most of their studied participants were in action and maintenance stage after participating in intervention program based TTM. The latter, had evaluated "stages of change for physical activity and dietary habits in persons with type 2 diabetes included in a mobile health intervention", showed that $79 \%$ of their studied subjects were in the pre-action stage for dietary change and indicated a requirement to provide more continual support for dietary change through intervention based TTM.

Moreover, the finding of this study indicated that, the majority of the studied pregnant women progressed in stages of change to action or maintenance stages after intervention based TTM. Only 5.5\% of them remained in the same stages (stationary). This finding was supported by the finding of Nitzke et al. ${ }^{[53]}$ who had evaluated "the effectiveness of an intervention to improve fruit and vegetable consumption of low-income young adults" pointed out that their participants in the intervention group had higher intakes of fruit and vegetables than those in control group and greater progression to action or maintenance stages after the intervention. Another interventional study applied the TTM in Konya, Turkey, was conducted by Koyun and Eroğlu ${ }^{[54]}$ reported that the rate of progression to action or maintenance stages were higher in the intervention group than in the control group after TTM based individual counseling.

Concerning TTM constructs toward diet behavior modification among the studied pregnant women, the findings of the current study revealed general improvements in all TTM constructs including self-efficacy, decisional balance ( pros) and process of change (experiential and behavioural) toward diet behavior modification of the studied pregnant women after intervention with highly statistically significant difference as compared to before intervention $(\mathrm{P}<.001)$. This evidence suggests that TTM-based interventions are more effective at improving self-efficacy, decisional balance pros and cons toward diet behavior modification. This result was supported by previously mentioned Huang et al. ${ }^{[51]}$ study, who showed that pregnant women in the study group had significantly higher post-test scores of self-efficacy, decisional balance of pros and process of change (experiential and behavioural) toward passive smoking prevention than pregnant women in the control group after intervention based TTM. Moreover, Mohsen et al. ${ }^{[55]}$ who had applied TTM to promote lifestyle behavior modification, stated that there was statistically improvement in the mean scores of studied subjects' self-efficacy, decisional balance ( pros) and process of change regarding dietary management behavior as a result of the intervention based TTM.

On the contrary, Bastani ${ }^{[56]}$ who had studied the effect of education on nutrition behavioral intention and self-efficacy on 104 women were recruited from premarital counselling clinics in Tehran. The researcher didn't find any significant difference in the nutrition self-efficacy score after the intervention. The difference between the current study result and Bastani study may be attributed to the difference in the targeted studied subjects where the current study targeted pregnant women with iron deficiency anemia while Bastani study targeted premarital women. In addition, our participants received diet education based on the TTM framework, that foster increasing efficacy expectations and perceived benefits (pros), and decreasing the negative perceptions (cons) while Bastani participants received nutritional education program didn't based on health promotion model or theory.

The correlations between pregnant women' subtotal score of TTM construct; total knowledge score and their stage of diet behaviour were investigated in the current study. Accordingly, there were a positive, highly statistically significant correlation $(\mathrm{P} \leq .01)$ between the studied pregnant women' scores of total knowledge, self-efficacy, pros of decisional balance, experiential and behavioural processes with their stage of diet behavior change before and after the intervention. This means that the studied pregnant women in the later stages (action, and maintenance) have a higher sores of knowledge, self-efficacy, decisional balance (pros), experiential and behavioural processes as compared to those in the preparation and contemplation stages.

The results of the current study agree with at least five other researches. First, Huang et al. ${ }^{[57]}$ who had assessed "the applicability of the trans-theoretical model to prevent exposure to passive smoking among pregnant women" through a cross-sectional survey, reported that pregnant women at the action and maintenance stage scored the highest grades in knowledge, self-efficacy and pros of decisional balance, followed by the women at the contemplation/preparation stage and the women at the precontemplation stage. Second Di Noia and Thompson. ${ }^{[58]}$ Who had studied "Processes of change for increasing fruit and vegetable consumption among economically disadvantaged African American adolescents" stated that the processes of change which 
include environmental reevaluation, consciousness raising, stimulus control and helping relationships were significantly associated with increasing fruit and vegetable consumption among their studied participants ( $\mathrm{p}<$ .01). third, Therawiwat et al. ${ }^{[59]}$. Who had conducted a study based TTM to determine factors related to stages of change regarding dietary intake of persons with metabolic syndrome. The study was carried out on five hundred persons. Researchers reported statistically positive correlation between self-efficacy and pros of decisional balance for dietary intake with the stages of change. Fourth, Keshani and Farvid [60] who had assessed "the association of self-efficacy and decisional balance with stages of change for fiber intake in 126 patients with diabetes" in Tehran-Iran. Found a relationship between TTM constructs such as self-efficacy across the stages of change with fiber intake among their studied participants, where the patients in the maintenance and action stages revealed higher self-efficacy than did those in the contemplation and preparation stages. Fifth, Ghannadiasl et al. ${ }^{[61]}$ who had assessed "the stages and processes of change, eating self-efficacy and decisional balance for weight loss in obese women attending nutrition clinics" and showed that the mean score of pre contemplation subscale was significantly lower than the mean total score of stages of change (P $<0.001)$ while the mean scores of action, and maintenance subscales were significantly greater $(\mathrm{P}<0.001)$.

Moreover, the current study showed a negative, highly statistically significant correlation $(\mathrm{P} \leq .01)$ between the score of decisional balance (cons) and the stage of diet behavior change before and after the intervention. This means that the studied pregnant women in the later stages (action, and maintenance) have lower sores of decisional balance (cons) as compared to those in the preparation and contemplation stages. Low con scores in the later stages (action, and maintenance) also suggest that pregnant women have perceived fewer cons about eating foods high in iron. This result was consistent with the study conducted by Emdadi et al. ${ }^{[62]}$ who had documented that decisional balance (cons) statistically decreased across the stages of behavior change, where their studied participants in pre-contemplation and contemplation stages scored the highest and those in action and maintenance stages scored lowest on cons. Also, previously mentioned Keshani and Farvid ${ }^{[60]}$ study, pointed out that the cons' scale was significantly different across the stages of change; in the pre-action stages it was higher than in the post-action ones.

The present study showed statistically significant difference $(\mathrm{P}<.05)$ before and after intervention regarding to the level of anemia and nearly one quarter of women were free from anemia. This goes in the same line with the study by Mastellos et al. ${ }^{[63]}$ who stated that after application of TTM stages of change there were improvements in physical activity and dietary habits, such as increased exercise duration and frequency, reduced dietary fat intake and increased fruit and vegetable consumption led to sustained weight loss. Also, previously mentioned Di Noia and Thompson ${ }^{[58]}$ study, found that promoting processes of change aid in increasing consumption of fruit and vegetable among economically disadvantaged African American adolescents.Therefore, to increase the awareness of pregnant women and improve their diet behavior modification, emphasis should be made on educational intervention based on health promotion models and continual evaluation of their knowledge and behaviors to prevent regress to a lower stage of behavior change when they encounter new difficulties or barriers.

\section{Conclusion}

Based on the results of the present study, it can be concluded that, the above mentioned results proved and reinforced the study hypothesis. The application of TTM of behavior change was effective in improving pregnant women's knowledge, diet behavior regarding IDA that was observed in increasing women's selfefficacy, pros, experiential and behavioral processes of change while decreasing cons post intervention as compared to pre intervention. Also, the findings highlight the importance of the TTM as a useful framework for promoting changes and evaluating participants' progress.

\section{Recommendations}

Based on findings of the current study, the following recommendations can be suggested:

- The nurse should implement educational intervention based on TTM for anaemic pregnant women regarding diet behaviour modification.

- The nurses should provide pregnant women at antenatal clinics with stage-matched intervention materials to improve their knowledge and diet behaviour.

- The curricula of nursing education should involve TTM of change as an effective health promotion model.

Further studies also recommended:

- Evaluating the effect of TTM of change on adoption of positive behaviour among pregnant women using a larger sample and different geographical areas in Egypt.

- $\quad$ Compare the effectiveness of TTM of change with other behavioural models.

\section{References}


[1] World Health Organization (WHO). The global prevalence of anaemia in 2011. Geneva: World Health Organization. 2015; Available at: http://www.who.int/ nutrition/ publications/ micronutrients/global_prevalence_anaemia_2011/e n/. Accessed on 9 th June 2015

[2] Kawaljit Kaur, B.D. Anaemia 'a silent killer' among women in India. Euro J Zool Res, 2014;3(1):32-36.

[3] Chowdhury, S., Rahman, M., \& Moniruddin, A.B.M. Anemia in pregnancy. Medicne Today, 2014 ; 26 (1): $49-52$.

[4] WHO, Micronutrient deficiencies: Prevention and control guidelines, 2015; Geneva, Switzerland.

[5] Krafft, A., Murray-Kolb, L., \& Milman, N. Anemia and iron deficiency in pregnancy. Hindawi Publishing Corporation: Journal of Pregnancy. 2012; 1. doi: 10.1155/2012/241869.

[6] Rome, S. I. Hematologic System. 2014; In S. L. Lewis, S. R. Dirkse, M. M. Heitkemper, \& L. Bucher Medical-surgical nursing: Assessment and management of clinical problems (613-631). St. Louis, MO: Elsevier

[7] Rezk, M., Marawan, H., Dawood, R., Masood, A., \& Abo-Elnasr M. Prevalence and risk factors of iron-deficiency anaemia among pregnant women in rural districts of Menoufia governorate, Egypt. J Obstet Gynaecol. 2015;35(7):663-666. doi: 10.3109/01443615.2014.991289. Epub 2015 Feb 2.

[8] Shill, K.B., Karmakar, P., Kibria ,G., Das, A., Rahman, M.A., Hossain, M.S., et al. Prevalence of iron-deficiency anaemia among university students in Noakhali region, Bangladesh. J Health Popul Nutr. 2014; 32(1):103-110.

[9] Abbaspour, N., Hurrell, R., \& Kelishadi, R. Review on iron and its importance for human health. J Res Med Sci. 2014;19:164-174.

[10] Balarajan, Y., Ramakrishnan, U, Ozaltin, E., Shankar, A.H., \& Subramanian S.V. Anaemia in low-income and middle-income countries. Lancet. 2011; 378(9809): 2123-2135. doi: 10.1016/S0140-6736(10)62304-5. Epub 2011 Aug 1.

[11] Kozuki, N,\& Lee, A.C., Katz, J. Moderate to severe, but not mild, maternal anemia is associated with increased risk of small-forgestational-age outcomes. J Nutr. 2012; 142:358-362. doi:10.3945/jn.111.149237

[12] WHO, United Nations Children's Fund, United Nations Population Fund, The World Bank, United Nations Population Division. Trends in maternal mortality: 1990 to 2010. Estimates by WHO, UNICEF, UNFPA, The World Bank and the United Nations Population Division. Geneva: World Health Organization, 2014 ; (http://apps.who.int/iris/bitstre am/10665/112682/2/9789241507226_eng.pdf?ua=1; accessed 7 May 2015).

[13] Bánhidy, F., Ács, N., Puhó, E. H., \& Czeizel, A. E. Iron deficiency anemia: Pregnancy outcomes with or without iron supplementation. Nutrition, 2011; 27(1): 65-72.

[14] Wessling-Resnick, M. In: Ross A.C., Caballero, B., Cousins R.J., \& Tucker K.L., Ziegler, R.G. Modern Nutrition in Health and Disease. $11^{\text {th }}$ ed. Baltimore, MD: Lippincott Williams \& Wilkins, 2014; 176-88.

[15] U.S. Department of Health and Human Services and U.S. Department of Agriculture. 2015 - 2020 Dietary Guidelines for Americans. ( $8^{\text {th }}$ Edition) December 2015; Available at http://health.gov/dietaryguidelines/2015/guidelines/.

[16] Government of western Australia, Department of health, Child and Antenatal Nutrition Manual School Aged Nutrition 4 - 11 years, June 2017; pp.13, 14

[17] Baby, A., Venugopal, J., D'silva, R., Chacko, S., Vineesha, P., \& Kumary, T.V. Knowledge on management of anemia during pregnancy: A descriptive study. Arch Med Health Sci. 2014; 2(2): 140-144.

[18] Fox, C. \& Kilvert, A . Intensive education for lifestyle change in diabetes. BMJ, 2003 ; 327: 1120-1121.

[19] Glanz, K., Rimer, BK., \& Viswanath, K. Health Behavior and Health Education: Theory, Research, and Practice, (4 ${ }^{\text {th }}$ edition), Jossey-Bass, San Francisco, 2008

[20] Rosen, C.S. Is the sequencing of change processes by stage consistent across health problems? A meta-analysis. Health. Psychol, 2000; 19(6):593-604.

[21] Koyun, A., \& Eroğlu, b.K. The trans theoretical model use for smoking cessation , European Journal of Research on Education , Special Issue: Contemporary Studies in Social Science, 2014; 130-134. Available Online at http://iassr.org/journal

[22] Yasin, S.M., Taib, K.M., \& Zaki, R.A. Reliability and construct validity of the Bahasa Malaysia version of transtheoretical model (TTM) questionnaire for smoking cessation and relapse among Malaysian adult. Asian Pac J Cancer Prev , 2011; 212(6): 14391443.

[23] Vivek, R.G., Halappanavar, A.B., Vivek, P.R., Halki, S.B., Maled, V.S. \& Deshpande, P.S. Prevalence of Anaemia and Its Epidemiological Determinants in Pregnant Women. Al Ameen Journal of Medical Sciences, 2012; 5, 216-223

[24] Cafasso, J. Iron Deficiency Anemia Secondary to Inadequate Dietary Iron Intake, Health line, 2016; pp.1-6

[25] Soleimani, N., \& Abbaszadeh, N. Relationship between anaemia, caused from the iron deficiency, and academic achievement among third grade high school female students. Procedia: Soc Behav Sci, 2011; 29:1877-1884.

[26] Global health estimates, summary tables: deaths by cause, age and sex, by WHO region, 2000-2012. Geneva: World Health Organization, 2014; (http://www.who.int/healthinfo/global_burden_disease/estimates/en/index1.html, accessed 25 March 2015)

[27] WHO. Vitamin and Mineral Nutrition Information System Evidence and Programme Guidance Unit Nutrition for Health and Development. 2015; Geneva.

[28] Humphreys, A., Thompson, N., \& Miner, K. Assessment of breastfeeding intention using the Trans theoretical Model and the Theory of Reasoned Action, 1998; 13 (3): 331-341.

[29] Kidd,P., Reed, D., Weaver, L., Westneat, S., \& Rayens, M. The transtheoretical model of change in adolescents: Implications for injury prevention, Journal of Safety Research, 2003; 34: 281- 28

[30] Janz, T.G., Johnson, RL., Rubenstein, SD. Anemia in the emergency department: evaluation and treatment, Emergency medicine practice. $2013 ; 15(11): 1-15$.

[31] Akhtar, M. \& Hassan, I. Severe Anaemia during Late Pregnancy. Case Reports in Obstetrics and Gynecology, 2012; Article ID: 485452. http://dx.doi.org/10.1155/2012/485452.

[32] Prakash, S. \& Yadav, K. Maternal Anemia in Pregnancy: An Overview, International journal of pharmacy and pharmaceutical research( Ijppr).Human, 2015; 4 (3): 164-179.

[33] De Menezes, M.C., Mingoti, S.A., Cardoso,C.S., Mendonça, D. R. \& Lopes, A.C.S . Intervention based on Transtheoretical Model promotes anthropometric and nutritional improvements-A randomized controlled trial. Eating behaviors, 2015; 17:37-44.

[34] Alemayehu, A., Gedefaw, L., Yemane ,T., \& Asres, Y. Prevalence, Severity, and Determinant Factors of anemia among pregnant women in South Sudanese Refugees, Pugnido, Western Ethiopia, Hindawi Publishing Corporation , 2016; 1-11.

[35] Yakout, S. M., Taha, N., Badawy, A.S. \& Al-Salooly, H.A the effect of iron supplementation and nutritional education among group of anemic pregnant women on their prenatal outcome in Riyadh, JCRSDJ., 2014; 2(1):41-47.

[36] Nwizu, E.N., Iliyasu, Z., Ibrahim, S.A., \& Galadanci, H.S. Socio-demographic and maternal factors in anaemia in pregnancy at booking in Kano, northern Nigeria. Afr J Reprod Health. 2011 Dec;15(4):33-41.

[37] Biswas, m., \& Baruah, R. Maternal anaemia associated with socio-demographic factors among pregnant women of Boko-Bongaon Block Kamrup, Assam. Indian Journal of Basic and Applied Medical Research; March 2014 3( 2): $712: 721$. 
[38] Sharma, P., Mehta, S., \& Nagar, R. Prevalence of anemia and socio-demographic factors associated with anemia among pregnant women attending antenatal Hospital in Jaipur City, India. IOSR Journal of Pharmacy and Biological Sciences. 2013; 6(3): 01-05.

[39] Mohammed .A. Anemia among Pregnant Women in Kelela Health Center, A thesis Submitted to department of Zoological Sciences, In Partial Fulfillment of the Requirements For the Degree of Master of Science In Biology South Wollo, Northeast Ethiopia, Addis Ababa, Ethiopia, 2016.

[40] Kraja, E., Caja, T. \& Petrela, E. Iron deficiency anaemia among pregnant women in Shokodra District : prevalence, attitude and practices, The 1st International Conference on Research and Education Challenges Toward the Future (ICRAE), 2013; 24-25 May

[41] Gebre, A., \& Mulugeta, A. Prevalence of Anemia and Associated Factors among Pregnant Women in North Western Zone of Tigray, Northern Ethiopia: A Cross-Sectional Study. J Nutr Metab. 2015;2015:165430. doi: 10.1155/2015/165430. Epub 2015 Jun 7.

[42] Salahat, M.A. \& Ibrahim, A.I. Prevalence of Anemia among Jordanian Pregnant Women and the Effect of Early Pregnancy on Alkaline Phosphatase Activity. Jordan Journal of Biological Sciences. 2012; 5(1): 65 - 70

[43] Okube, Q.T., Mirie,1.W., Odhiambo, E., Sabina, W. \& Habtu , M. Prevalence and Factors Associated with anaemia among Pregnant Women Attending Antenatal Clinic in the Second and Third Trimesters at Pumwani Maternity Hospital ,Kenya, Open Journal of Obstetrics and Gynecology, 2016; 6, 16-27

[44] Selim, N.A.A., Al-Mass, M., Al-Kuwari, M. \& Ismail, M.S. Assessment of Anemia, IDA and ID among Pregnant in Qatar: Cross Sectional Survey. SM J Public Health Epidemiol. 2016; 2(3): 1035

[45] Ghimire, N., Pandey, N. (2016): knowledge and practice of mothers regarding the prevention of anemia during pregnancy in Teaching Hospital Kathmandu, Ghimire et al, Journal of Chitwan Medical College 2013; 3(5): 14-17.

[46] Shanthini, N,F., Nivedita, K. Knowledge, attitude and practices of pregnant women regarding anemia, iron rich diet and iron supplements and its impact on their hemoglobin levels, Int J Reprod Contracept Obstet Gynecol. 2016; 5(2): 425-431

[47] Balasubramanian, T., Aravazhi, M. \& Sampath,S. D. Awareness of Anemia among Pregnant Women and Impact of Demographic Factors on their Hemoglobin Status, International Journal of Scientific Study. 2016; 3(12): 303:305.

[48] Abd ElHameed, H.S., Mohammed, A.I., \& Abd El Hameed, L.T. Effect of Nutritional Educational Guideline among Pregnant Women with Iron Deficiency Anemia at Rural Areas in Kalyobia Governorate. Life Science Journal 2012; 9( 2): 1212-1217.

[49] Khoramabadi, M., Dolatian, M., Hajian, S., Zamanian, M., Taheripanah, R., Sheikhan, Z., Mahmoodi, Z., \& Seyedi-Moghadam A. Effects of Education Based on Health Belief Model on Dietary Behaviors of Iranian Pregnant Women. Glob J Health Sci. 2015; 8(2):230-9. doi: 10.5539/gjhs.v8n2p230.

[50] Huang, C.M., Guo, J.L., Guo, H.J., Lee, M.Y., and Shen, W.P. Using the transtheoretical model to develop educational media to promote smoking cessation in pregnant and postpartum women. Hu Li Za Zhi. 2009; 56(6):87-94.

[51] Huang, C.M., Wu, H.L., Huang, S.H., Chien, L.Y., \& Guo, J.L. Transtheoretical modelbased passive smoking prevention programme among pregnant women and mothers of young children. Eur J Public Health. 2013; 23(5):777-782. doi: 10.1093/eurpub/cks177. Epub 2013 Jan 15.

[52] Holmen, H., Wahl, A., Torbjørnsen, A, Jenum, A.K, Småstuen, M.C., \& Ribu, L. Stages of change for physical activity and dietary habits in persons with type 2 diabetes included in a mobile health intervention: the Norwegian study in renewing health. BMJ Open Diabetes Res Care. 2016; 4(1): 1-1. e000193. doi: 10.1136/bmjdrc-2016-000193. eCollection 2016.

[53] Nitzke, S., Kritsch, K., Boeckner, L., Greene, G., Hoerr, S., Horacek, T., Kattelmann, K., Lohse, B., Oakland, M.J., Beatrice, P., \& White, A. A. stage-tailored multi-modal intervention increases fruit and vegetable intakes of low-income young adults. Am J Health Promot. 2007;22(1):6-14.

[54] Koyun, A., \& Eroğlu, K. The effect of transtheoretical model-based individual counseling, training, and a 6-month follow-up on smoking cessation in adult women: a randomized controlled trial. Turk J Med Sci. 2016;46(1):105-11. doi: 10.3906/sag-1407-100.

[55] Mohsen, M.M, Saafan, N.A., Attia, A., \& El-Abassy, A. Lifestyle Behavior Modification of Mothers of Diabetic Children's through Application of Trans-theoretical Model of Change. J Nurs Care. 2014; 3(2): 1-10. doi:10.4172/2167-1168.1000153

[56] Bastani, F. The Effect of Education on Nutrition Behavioral Intention and Self Efficacy in Women. J Health Scope.2012; 1(1):1217. DOI: $10.5812 / \mathrm{JHS} .4520$

[57] Huang, C.M., Guo, J.L., Wu, H.L., \& Chien, L.Y. Stage of adoption for preventive behaviour against passive smoking among pregnant women and women with young children in Taiwan. J Clin Nurs. 2011; 20(23-24):3331-3338. doi: 10.1111/j.13652702.2011.03803.x. Epub $2011 \mathrm{Jul} 21$.

[58] Di Noia, J. \& Thompson, D. Processes of change for increasing fruit and vegetable consumption among economically disadvantaged African American adolescents. Eat Behav. 2012; 13(1):58-61. doi: 10.1016/j.eatbeh.2011.10.001. Epub 2011 Oct 25.

[59] Therawiwat M, Imamee N, Khamklueng T. Self-efficacy, decisional balance and stages of change on dietary practices among metabolic syndrome persons, Uthai Thani Province. J Med Assoc Thai. 2013;96 Suppl 5:S131- S137.

[60] Keshani, P., \& Farvid, M.S. Association of Self-efficacy and Decisional Balance with Stages of Change for Fiber Intake and Glycemic Control in Patients with Type 2 Diabetes. Nutrition and Food Sciences Research. 2015; 2(4): 11-20.

[61] Ghannadiasl, F., Mahdavi, R., \& Jafarabadi, M.A. Assessment of Stages and Processes of Change, Eating Self-Efficacy and Decisional Balance forWeight Loss in ObeseWomen Attending Nutrition Clinics. Jundishapur J Health Sci. Published online 2016 ; (inpress):e42088.

[62] Emdadi, S.h., Nilsaze, M., Hosseini, B., \& Sohrabi, F. Application of the Trans-Theoretical Model (TTM) to Exercise Behavior among Female College Students. J Res Health Sci. 2007;7(2):25-30.

[63] Mastellos, N., Gunn, L.H., Felix, L.M., Car, J., Majeed, A. Transtheoretical model stages of change for dietary and physical: exercise modification in weight loss management for overweight and obese adults, Cochrane Database Syst Rev, 2014; 5 (2) 